\title{
In-Vitro Wound Healing, Antioxidants, Antibacterial and Cytotoxic Activity of Probiotic Bacteria Isolated from Spoilled Curd ${ }^{\dagger}$
}

\author{
Jenifer T. ${ }^{1, *}$ \\ 1 St. Joseph's College of Engineering, OMR, Chennai \\ * Correspondence: jenirefi@gmail.com; \\ $\dagger$ Presented at International e-Conference on Bioengineering for Health and Environment (ICBHE 2020)
}

Received: 5.07.2020; Revised: 10.07.2020; Accepted: 12.07.2020; Published: 15.07.2020

\begin{abstract}
Lactic acid bacteria (LAB) isolated from curd has emerged as a welcome source of antimicrobials and therapeutics and is accepted as probiotics. Probiotics have been associated with improved healing of intestinal ulcers and healing of infected cutaneous wounds. Therefore this current study was undertaken to assess the antibacterial, antioxidant, minimum inhibitory concentration, and cytotoxicity efficacy of Lactobacilli isolated from the spoiled curd sample. The bacteria were isolated using the serial dilution method and the antagonistic properties of these isolates against Bacillus subtilis, Staphylococcus aureus, Escherichia coli, and Pseudomonas aeruginosa were examined using agar well diffusion method. Amongst the 8 isolates, $\mathrm{C} 3$ exhibited the highest antibacterial activity against all the pathogens. It was then tested for an antioxidant property using the DPPH assay and also found wound healing property using a $3 \mathrm{~T} 3$ cell line. This review points to a new perspective and therapeutic potential of beneficial probiotic species as a safe alternative approach for the treatment of patients affected by cutaneous wounds.
\end{abstract}

Keywords: Lactic acid bacteria; Antibacterial activity; Antioxidant activity; DPPH assay; wound healing.

(C) 2020 by the authors. This article is an open-access article distributed under the terms and conditions of the Creative Commons Attribution (CC BY) license (https://creativecommons.org/licenses/by/4.0/).

\section{Funding}

This research received no external funding.

\section{Acknowledgments}

This research has no acknowledgment.

\section{Conflicts of Interest}

The authors declare no conflict of interest. 